OPEN ACCESS

Edited by:

Yi Zhu,

Peking University Health Science

Center, China

Reviewed by:

Wei Kong,

Peking University Health Science

Center, China

Yunzeng Zou,

Fudan University, China

*Correspondence: Ishag Adam,

Faculty of Medicine, University of Khartoum, Alkaser Street, PO Box 102, Khartoum, Sudan ishagadam@hotmail.com

Specialty section:

This article was submitted to Vascular Physiology,

a section of the journal Frontiers in Physiology

Received: 04 March 2015 Accepted: 02 May 2015 Published: 18 May 2015

Citation:

Mohamed RE, Gadour MO and Adam I (2015) The lowering effect of Gum Arabic on hyperlipidemia in Sudanese patients. Front. Physiol. 6:160. doi: 10.3389/fphys.2015.00160

\section{The lowering effect of Gum Arabic on hyperlipidemia in Sudanese patients}

\author{
Rima E. Mohamed ${ }^{1}$, Mohammed O. Gadour ${ }^{1}$ and Ishag Adam ${ }^{1,2 *}$ \\ ${ }^{1}$ Faculty of Medicine, Omdurman University, Omdurman, Sudan, ${ }^{2}$ Faculty of Medicine, University of Khartoum, Khartoum, \\ Sudan
}

Hyperlipidemia especially low density lipoprotein cholesterol (LDL-C) is a major risk factor for developing ischemic heart disease. Soluble dietary fiber has lipid lowering characteristics. Gum Arabic (GA) is $95 \%$ soluble fiber calculated on dry bases. The beneficial effect of GA on lipid profile needs further verification. A case-control study was conducted at Omdurman Hospital, Sudan to assess the effect of $G$ A on serum lipids in patients with hyperlipidemia. Cases received a $20 \mathrm{mg}$ tablet of atorvastatin /day plus $30 \mathrm{mg}$ of GA for 4 weeks while the controls received atorvastatin only. Levels of lipids in serum were assessed according to conventional methods before and 1 month after the trial. There is no significant difference in the basic characteristics between the study and the control groups (55 patients in each arm of the study). While there was no significant difference in the levels of HDL, there was a significant reduction of the total cholesterol (25.9 vs. $7.8 \%, P<0.001$ ), triglyceride (38.2 vs. $2.9 \%, P<0.001$ ), and LDL (30.8 vs. $8.1 \%, P<0.001$ ) before and after the intervention in the study compared to the controls groups.

Keywords: hyperlipidemia, hypercholestrolemia, Gum Arabic, Sudan

\section{Introduction}

It has been shown that elevated cholesterol level -especially low density lipoprotein cholesterol (LDL-C)-is a major risk factor for coronary heart disease (CHD) which is a leading cause of death worldwide. Soluble dietary fiber has a lipid-lowering property (Pekkanen et al., 1990). The Adult Treatment Panel III (ATP III) of the National Cholesterol Education Program (NCEP) issued an evidence-based set of guidelines on cholesterol management in which they encouraged use of viscous (soluble) fiber (e.g., oats, guar, pectin, and psyllium) as therapeutic dietary options to enhance lowering of LDL cholesterol in primary and secondary prevention of CHD(NCEP, 2002) Gum Arabic (GA) which is mixture of polysaccharides, oligosaccharides and glycoproteins is exudates of Acacia Senegal/seyal trees (Anderson and Stoddart, 1966; Goodrum et al., 2000). GA is defined by the $\mathrm{FAO} / \mathrm{WHO}$ Joint Expert Committee as an exudation obtained from the stems of Acacia Senegal or closely related other species of Acacia (FAO/WHO, 1969; FAO, 1990). It is water soluble; therefore it is used as an emulsifier, thickening substance and flavor stabilizer in many pharmaceutical and food industries (Dziezak, 1991). Interestingly, since 1969 GA was evaluated for acceptable daily intake for man by the Joint FAO/WHO Expert Committee on Food Additives since 1969 (FAO/WHO, 1969; FAO, 1990). GA is indigestible to humans, but following its fermentation in the colon short-chain fatty acids are produced that can lead a lot of benefits such as prebiotic effect, increases in Bifidobacteria, Lactobacteria, and Bacteriodes reflecting a prebiotic effect (Calame et al., 2008; Phillips et al., 2008; Phillips and Phillips, 2011), anticarcinogenic effect and anti-oxidant effect (Sharma, 1985; Al-Majed et al., 2002; Ali et al., 2003; Nasir et al., 2010). 
Other effects of GA include reduction in plasma cholesterol level in animals and humans (Sharma, 1985). Lowering effect of GA on lipid profile that has been mentioned in some studies needs further verification and more research is necessary (Kelley and Tsai, 1978; Ross et al., 1983; Sharma, 1985; Mee and Gee, 1997). The aim of this study was to determine the effects of GA ingestion on lipids profile among adults Sudanese patients with hyperlipidemia.

\section{Materials and Methods}

\section{Patients}

A case-control was conducted at Omdurman Hospital Sudan during the period of June-December 2012 where patients with hyperlipidemia (total cholesterol $>200 \mathrm{mg} / \mathrm{dl}$, LDL > $100 \mathrm{mg} / \mathrm{dl}), \mathrm{HDL}<40 \mathrm{mg} / \mathrm{dl}$, triglyceride $>150 \mathrm{mg} / \mathrm{dl}$ were enrolled to the study. A sample size of 55 subjects per group was calculated to detect a significant reduction in lipid profile $15-25 \%$, with a two-sided 5\% significance level and a power of 80\% (Whitley and Ball, 2002).

The patients with newly discovered hyperlipidemia were enrolled (if they were not on lipid lowering agent for at least 1 month before starting the study. Patients who had familial hyperlipidemia, premature CHD, pregnant, and lactating ladies were excluded. Using computer generated number and sealed envelopes patients were assigned to the study group received atorvastatin tablet, $20 \mathrm{mg}$ plus $30 \mathrm{mg}$ of GA which was a natural gum provided in a powder form by the expertise "Dar Savanna Ltd. Khartoum, Sudan" that provided it for the research before (Babiker et al., 2012) and control group received statin only. Both statin and GA were used at bedtime. The socio-demographic, medical history was taken from each patient using questionnaire. The control groups were advised not to take GA by themselves (it is widely used in Sudan). The diet and exercise were kept under control in both the study and controls groups. Then $5 \mathrm{ml}$ of venous blood was taken from each respondent to measure lipid profile (total, LDL and HDL cholesterol and triglycerides) using a multichannel chemistry auto analyzer Lipid profiles, were determined for each participant twice; at baseline of the study and after 4 weeks. Compliance was monitored by weekly contact with the subjects by phone.

\section{Statistics}

Data were entered using SPSS for Windows V.16.0 (SPSS Inc., Chicago, IL, USA. The paired $t$-test was used for analysis of pre and post intervention levels of the lipid profile. Mean (SD) and proportion were compared between the study and control groups using independent sample $t$-test and $\mathrm{X}^{2}$, respectively. A $p$-value of less than 0.05 was regarded statistically significant.

\section{Ethics}

The study received ethical clearance from the board of ethical committee of Ministry of Health Khartoum State, Sudan. Confidentiality and privacy of respondents was assured. All responses were kept anonymous. Coding (Identification numbers) was used to identify the data collection form.

\section{Results}

One hundred and twenty patients with hyperlipidemia who met the inclusion and exclusion criteria were enrolled to the study. Out of these 120, 110 completed the study through the end of the 4 -weeks treatment period. Ten ( 5 in each group) participants dropped due to loss of follow-up. There was no significant difference in the mean (SD) of the age [54.7(10.4) vs. 55.2(11.3) years, $P=0.809$ ], body mass index [29.7 (7.2) vs. 29.1(6.5)

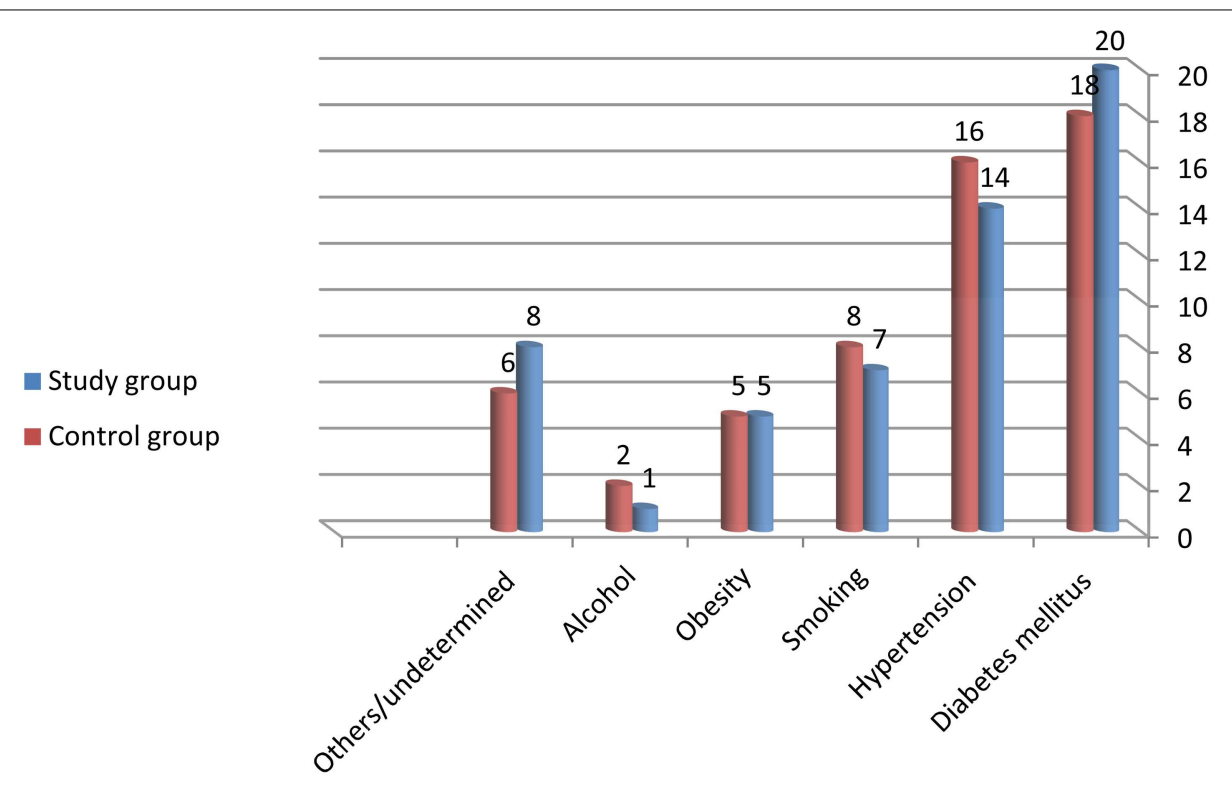

FIGURE 1 | Different causes of the hyperlipidemia in the study and control group. 
$\left.\mathrm{kg} / \mathrm{cm}^{2}, P=0.454\right]$ and the number (\%) of female [31(56.4\%) vs. 30 (54.5\%), $p>0.999$ ] between the study and the control groups.

Different causes of hyperlipidemia were observed and these were not different between the study and control groups, Figure 1.

While there was no significant difference in the levels of HDL, there was a significant reduction of the total cholesterol (25.9 vs. $7.8 \%, P<0.001)$, triglyceride (38.2 vs. $2.9 \%, P<0.001)$ and LDL (30.8 vs. $8.1 \%, P<0.001$ ) in the study compared to the controls groups, Table 1, and Figure 2.

\section{Discussion}

The main finding of the current study is the lowering effect of the GA on the lipid levels (with exception of HDL) in patients with hyperlipidemia. This goes with the previous findings from other studies that have reported lipid-lowering effects of soluble dietary fiber (Ross et al., 1983; Judd and Truswell, 1985; Sharma, 1985; Anderson et al., 1991; Glore et al., 1994). However, Haskell et al. (1992) showed that a low-viscosity acacia gum at a dose of $15 \mathrm{~g} / \mathrm{d}$ had no effect on the lipid profile compared to placebo. Likewise, Davidson et al. (1998) observations did not support the hypocholesterolemic effect of the GA/pectin. The variable lipid lowering effects of GA might be related to the dose used, the chemical constituents of GA that can vary with its source or may be due to genetic and personal differences (Judd and Truswell, 1985; Islam et al., 1997; Verbeken et al., 2003). It has been reported that dietary fibers including GA bind bile acids and diminish their absorption in the terminal ileum (Moundras et al., 1994). Then in the large intestine, breakdown of GA releases

TABLE 1 | Changes of the lipids profile in the study and control groups before and after the trial.

\begin{tabular}{|c|c|c|c|c|c|}
\hline Variable & & $\begin{array}{l}\text { Mean } \\
\text { (SD) }\end{array}$ & $\begin{array}{l}\text { Mean (\%) } \\
\text { difference }\end{array}$ & $P$ & $P$ \\
\hline \multirow[t]{2}{*}{ Cholesterol (study group) } & Before & $226.4(9.0)$ & 58.7 (25.9) & $<0.001$ & $<0.001$ \\
\hline & After & $167.6(3.6)$ & & & \\
\hline \multirow[t]{2}{*}{ Cholesterol (control group) } & Before & $225.9(8.7)$ & $17.8(7.8)$ & $<0.001$ & \\
\hline & After & $208.0(6.4)$ & & & \\
\hline \multirow[t]{2}{*}{ Triglyceride (study group) } & Before & $171.6(13.3)$ & $65.5(38.2)$ & $<0.001$ & $<0.001$ \\
\hline & After & $106.0(7.1)$ & & & \\
\hline \multirow[t]{2}{*}{ Triglyceride (control group) } & Before & $172.6(13.0)$ & $5.1(2.9)$ & 0.005 & \\
\hline & After & $167.4(1.7)$ & & & \\
\hline \multirow[t]{2}{*}{ HDL (study group) } & Before & $45.9(4.6)$ & 1.5 (3.3) & 0.172 & 0.945 \\
\hline & After & $44.4(6.6)$ & & & \\
\hline \multirow[t]{2}{*}{ HDL (control group) } & Before & $46.0(4.6)$ & $1.6(3.6)$ & 0.136 & \\
\hline & After & $44.4(6.6)$ & & & \\
\hline \multirow[t]{2}{*}{ LDL (study group) } & Before & $141.2(13.0)$ & $43.6(30.8)$ & $<0.001$ & $<0.001$ \\
\hline & After & $97.6(4.5)$ & & & \\
\hline \multirow[t]{2}{*}{ LDL (control group) } & Before & $142.5(11.7)$ & $11.5(8.1)$ & $<0.001$ & \\
\hline & After & $130.9(1.3)$ & & & \\
\hline
\end{tabular}

the sequestered bile acids and the acidic $\mathrm{pH}$ generated during the fermentation process renders them insoluble and promotes their excretion in stool (Moundras et al., 1994). This process reduces the lipid pool in the body and causes decreased fat digestion

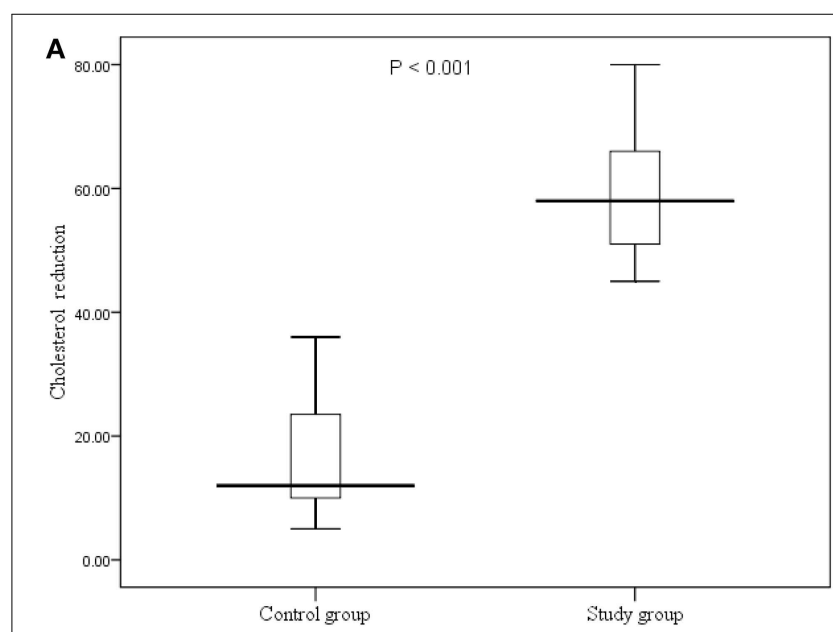

B

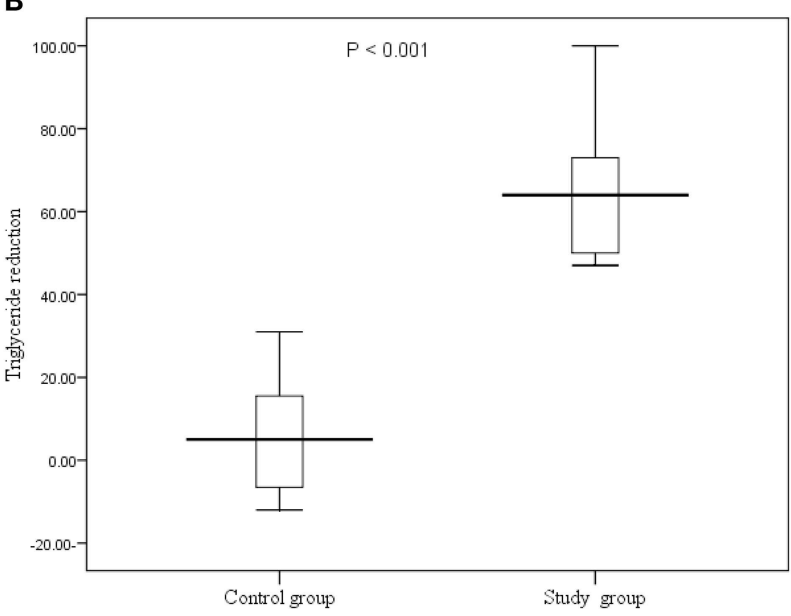

C

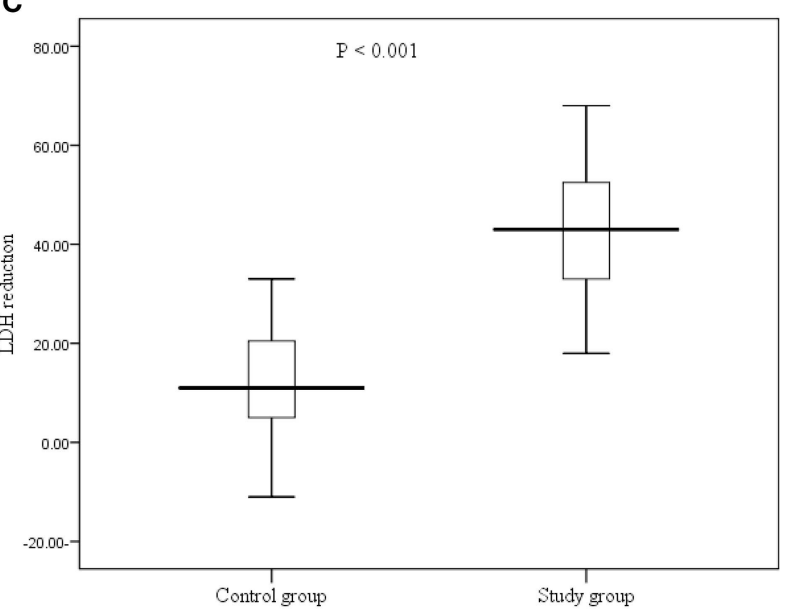

FIGURE 2 | (A-C) Reduction of the lipids (cholesterol, triglyceride and LDL profile in the study and control groups before and after the trial. 
and absorption. Likewise, the liver formation of new bile acids requires cholesterol. Thus, prolonged ingestion of GA may lead to reduction in cholesterol level in plasma. Interestingly a more a recent proposed mechanism by which viscous dietary fibers can reduce adiposity is increased mitochondrial biogenesis and fatty acid oxidation by skeletal muscles (Islam et al., 2012).

\section{References}

Ali, B. H., Al-Qarawi, A. A., Haroun, E. M., and Mousa, H. M. (2003). The effect of treatment with Gum Arabic on gentamicin nephrotoxicity in rats: a preliminary study. Ren. Fail. 25, 15-20. doi: 10.1081/JDI-120017439

Al-Majed, A. A., Mostafa, A. M., Al-Rikabi, A. C., and Al-Shabanah, O. A. (2002). Protective effects of oral arabic gum administration on gentamicin-induced nephrotoxicity in rats. Pharmacol. Res. 46, 445-451 doi: $10.1016 /$ S1043661802001251

Anderson, D. M. W., and Stoddart, J. F. (1966). Studies on uronic acid materials: part XV. The use of molecular-sieve chromatography in studies on acacia senegal gum (Gum Arabic). Carbohydr. Res. 2, 104-114.

Anderson, J. W., Floore, T. L., Geil, P. B., O’Neal, D. S., and Balm, T. K. (1991). Hypocholesterolemic effects of different bulk-forming hydrophilic fibers as adjuncts to dietary therapy in mild to moderate hypercholesterolemia. Arch. Intern. Med. 151, 1597-1602. doi: 10.1001/archinte.151.8.1597

Babiker, R., Merghani, T. H., Elmusharaf, K., Badi, R. M., Lang, F., and Saeed, A. M. (2012). Effects of Gum Arabic ingestion on body mass index and body fat percentage in healthy adult females: two-arm randomized, placebo controlled, double-blind trial. Nutr. J. 11:111. doi: 10.1186/1475-2891-11-111

Calame, W., Weseler, A. R., Viebke, C., Flynn, C., and Siemensma, A. D. (2008). Gum Arabic establishes prebiotic functionality in healthy human volunteers in a dose-dependent manner. Br. J. Nutr. 100, 1269-1275. doi: 10.1017/S0007114508981447

Davidson, M. H., Dugan, L. D., Stocki, J., Dicklin, M. R., Maki, K. C., Coletta, F., et al. (1998). A low-viscosity soluble-fiber fruit juice supplement fails to lower cholesterol in hypercholesterolemic men and women. J. Nutr. 128, 1927-1932.

Dziezak, J. D. (1991). A focus on gums. Food. Technol. 45, 116-132.

FAO. (1990). Gum Arabic. Food and Nutrition, 23rd Edn. Paper 49. Rome.

FAO/WHO. (1969). Evaluations of some pesticide residues in food. FAO/PL: 1969/M/17/1; WHO/Food Add./70.38. 1970, 145-177. on INCHEM. doi: 10.1056/NEJM199006143222403

Glore, S. R., Van Treeck, D., Knehans, A. W., and Guild, M. (1994). Soluble fiber and serum lipids: a literature review. J. Am. Diet Assoc. 94, 425-436. doi: 10.1016/0002-8223(94)90099-X

Goodrum, L. J., Patel, A., Leykam, J. F., and Kieliszewski, M. J. (2000). Gum Arabic glycoprotein contains glycomodules of both extensin and arabinogalactanglycoproteins. Phytochemistry 54, 99-106. doi: 10.1016/S0031-9422(00)00043-1

Haskell, W. L., Spiller, G. A., Jensen, C. D., Ellis, B. K., and Gates, J. E. (1992). Role of water-soluble dietary fiber in the management of elevated plasma cholesterol in healthy subjects. Am. J. Cardiol. 69, 433-439 doi: 10.1016/00029149(92)90980-D

Islam, A., Civitarese, A. E., Hesslink, R. L., and Gallaher, D. D. (2012). Viscous dietary fiber reduces adiposity and plasma leptin and increases muscle expression of fat oxidation genes in rats. Obesity 20, 349-355. doi: 10.1038/oby.2011.341

Islam, A. M., Phillips, G. O., Sljivo, M. J., and Williams, P. A. (1997). A review of recent developments on the regulatory, structural and functional aspects of gum arabic. Food. Hydrocoll. 11, 493-505. doi: 10.1016/S0268-005X(97) 80048-3

Judd, P. A., and Truswell, A. S. (1985). "Dietary fiber and blood lipids in man," in Dietary Fiber Perspectives-Reviews and Bibliography, ed A. R. Leeds (London: John Libbey), 23-39.
In summary, the current study showed a statistically significant reduction in total cholesterol, triglyceride and LDL with in the study group (GA) compared to the control group. Prospective studies with larger number of participants and longer duration together with the evaluation of the effect of GA alone on lipid profile are needed.

Kelley, J. J., and Tsai, A. (1978). Effect of pectin, gum arabic and agar on cholesterol absorption, synthesis, and turnover in rats. J. Nutr. 108, 630-639

Mee, K. M., and Gee, D. L. (1997). Apple fiber and gum arabic lowers total and lowdensitylipoprotein cholesterol levels in men with mild hypercholesterolemia. J. Am. Diet. Assoc. 97, 422-423 doi: 10.1016/S0002-8223(97) 00106-5

Moundras, C., Behr, S. R., Demigné, C., Mazur, A., and Rémésy, C. (1994). Fermentable polysaccharides that enhance fecal bile acid excretion lower plasma cholesterol and apolipoprotein E-rich HDL in rats. J. Nutr. 124, 2179-2188

Nasir, O., Wang, K., Föller, M., Bhandaru, M., Sandulache, D., Artunc, F., et al. (2010). Downregulation of angiogenin transcript levels and inhibition of colonic carcinoma by Gum Arabic (Acacia senegal). Nutr. Cancer. 62, 802-810. doi: 10.1080/016355810036 05920

NCEP. (2002). Third report of the National Cholesterol Education Program (NCEP) expert panel on detection, evaluation, and treatment of high blood cholesterol in adults (Adult Treatment Panel III) final report. Circulation 106, 3143-3421.

Pekkanen, J., Linn, S., Heiss, G., Suchindran, C. M., Leon, A., Rifkind, B. M., et al. (1990). Ten-year mortality from cardiovascular disease in relation to cholesterol level among men with and without preexisting cardiovascular disease. N. Engl. J. Med. 322, 1700-1707. doi: 10.1056/NEJM19900614 3222403

Phillips, A. O., and Phillips, G. O. (2011). Biofunctional behaviour and health benefits of a specific Gum Arabic. Food Hydrocolloids 25, 165-169.

Phillips, G. O., Ogasawara, T., and Ushida, K. (2008). The regulatory and scientific approach to defining Gum Arabic (acacia senegal and acacia seyal) as a dietary fibre. Food Hydrocolloids 22, 24-35. doi: 10.1016/j.foodhyd.2006. 12.016

Ross, A. H., Eastwood, M. A., Brydon, W. G., Anderson, J. R., and Anderson, D. M. (1983). Astudy of the effects of dietary gum arabic in humans. Am. J. Clin. Nutr. 37, 368-375. doi: 10.1056/NEJM199006143 222403

Sharma, R. D. (1985). Hypocholesterolemic effect of gum acacia in men. Nutr. Res. 5, 1321-1326. doi: 10.1016/S0271-5317(85)80042-7

Verbeken, D., Dierckx, S., and Dewettinck, K. (2003). Exudate gums: occurrence, production, and applications. Appl. Microbiol. Biotechnol. 63, 10-21. doi: $10.1007 /$ s00253-003-1354-z

Whitley, E., and Ball, J. (2002). Statistics review 5: comparison of means. Crit. Care 6, 424-428. doi: $10.1186 / \mathrm{cc} 1548$

Conflict of Interest Statement: The authors declare that the research was conducted in the absence of any commercial or financial relationships that could be construed as a potential conflict of interest.

Copyright (c) 2015 Mohamed, Gadour and Adam. This is an open-access article distributed under the terms of the Creative Commons Attribution License (CC $B Y)$. The use, distribution or reproduction in other forums is permitted, provided the original author(s) or licensor are credited and that the original publication in this journal is cited, in accordance with accepted academic practice. No use, distribution or reproduction is permitted which does not comply with these terms. 